\title{
Spontaneous Pneumothorax during the Recovery Phase of Coronavirus Disease-19 Pneumonia
}

\author{
Begum Oktem, Tarık Yağcı' ${ }^{1}$, Fatih Uzer² \\ Departments of Emergency Medicine, ${ }^{\top}$ Thoracic Surgery and ${ }^{2}$ Respiratory Disease, Kastamonu State Hospital, Kastamonu, Turkey
}

\section{Abstract}

There is not enough information about short- and long-term complications of coronavirus disease 2019 (COVID-19) infection, following treatment. Pneumothorax due to barotrauma after adult respiratory distress syndrome has been observed in some viral infections. However, spontaneous pneumothorax occurring after treatment is uncommon. We report a case of chronic obstructive pulmonary disease (COPD), who presented to the emergency department with pneumothorax 1 month after receiving treatment for COVID-19 infection. The patient had shortness of breath starting 3 weeks after discharge. He had a history of hospitalization due to a COPD attack within the past year. He was diagnosed as pneumothorax with radiological imaging.

Keywords: Chronic obstructive pulmonary disease, coronavirus disease 2019, pneumothorax

\section{INTRODUCTION}

Coronavirus disease 2019 (COVID-19) infection was first identified in Wuhan, China, during late 2019. It was declared as a pandemic by the World Health Organization (WHO) in March 2020. ${ }^{[1]}$ The infection has become widespread and has become a global problem. Clinically, COVID-19 infection reveals itself with fever, myalgia, respiratory symptoms, and gastrointestinal symptoms, and it can lead to metabolic acidosis, septic shock, coagulopathy, and acute respiratory distress syndrome (ARDS). ${ }^{[1,2]}$

COVID-19 infection can be superimposed on many chronic diseases. It is reported that the most common of these, especially hypertension and diabetes mellitus, can result in negative clinical outcomes. However, coexistence with chronic lung diseases is rare. ${ }^{[3]}$

Lung findings in patients with COVID-19 diagnosis can differ. Studies have shown that consolidations and ground-glass densities are common findings. However, other findings such as pleural fluid and atelectasis are rarely seen. ${ }^{[1,2]}$ There is not enough information about short- and long-term complications of COVID-19 infection following treatment. Pneumothorax due to barotrauma after ARDS has been observed in some viral infections. ${ }^{[4]}$ However, spontaneous pneumothorax occurring after treatment is not common.

\begin{tabular}{|l|l|}
\hline \multicolumn{2}{|c|}{ Access this article online } \\
\hline Quick Response Code: & Website: \\
& www.ijrc.in \\
& \\
&
\end{tabular}

We present a patient with chronic obstructive lung disease (chronic obstructive pulmonary disease [COPD]), diagnosed to have COVID-19 infection and successfully treated, who was brought to the emergency department with pneumothorax after a month.

\section{Case Report}

A 79-year-old male was admitted to the emergency department with a complaint of shortness of breath for 8 days. His initial vital signs were as follows: blood pressure of $120 / 80 \mathrm{mmHg}$, heart rate 106 beats $/ \mathrm{min}$, and a temperature of $36.7^{\circ} \mathrm{C}$. Upon physical examination, no lung sounds were heard on the left chest, and there were crackles heard on the right chest. His systemic examination was otherwise normal. He had a prior history of COPD, was hospitalized for COPD exacerbation within the last year, and was on regular follow-up. He was hospitalized with COVID-19 diagnosis 32 days ago.

Address for correspondence: Dr. Fatih Uzer, Department of Respiratory Disease, Kastamonu State Hospital, Kastamonu, Turkey. E-mail: uzerfatih@gmail.com

This is an open access journal, and articles are distributed under the terms of the Creative Commons Attribution-NonCommercial-ShareAlike 4.0 License, which allows others to remix, tweak, and build upon the work non-commercially, as long as appropriate credit is given and the new creations are licensed under the identical terms.

For reprints contact: WKHLRPMedknow_reprints@wolterskluwer.com

How to cite this article: Oktem B, Yağc1 T, Uzer F. Spontaneous pneumothorax during the recovery phase of coronavirus disease-19 pneumonia. Indian J Respir Care 2021;10:116-9.

Received: $19-07-2020$

Accepted: $27-09-2020$

Revised: 16-09-2020 Published: $31-01-2021$ 
Oktem, et al.: COVID-19 and pneumothorax

He was an ex-smoker with a history of 45 pack-years of smoking. His family history was unremarkable. He was using $18 \mathrm{mcg}$ tiotropium inhalation capsule once a day and $50 \mathrm{mcg}$ salmeterol $+500 \mathrm{mcg}$ fluticasone propionate through inhalation twice a day for COPD. During his hospitalization for 8 days with COVID-19 diagnosis, he was treated with hydroxychloroquine sulfate with an initial dose of $800 \mathrm{mg}$ and followed by a maintenance dose of $400 \mathrm{mg} /$ day, $75 \mathrm{mg}$ oseltamivir twice a day, methylprednisolone $40 \mathrm{mg} /$ day, and meropenem trihydrate $1 \mathrm{~g}$ three times a day, for 5 days.

His initial laboratory values of blood sample in the emergency department were as follows: hemoglobin $12.8 \mathrm{~g} / \mathrm{dl}$, leukocytes 11830 cells $/ \mu \mathrm{L}$, lymphocytes 530 cells $/ \mu \mathrm{L}$, D-dimer $4.68 \mathrm{mg} / \mathrm{L}$, C-reactive protein $151.7 \mathrm{mg} / \mathrm{L}$, creatinine $1.02 \mathrm{mg} / \mathrm{dL}$, prothrombin time $10.9 \mathrm{~s}$, INR 0.95 , and activated partial thromboplastin time $19.5 \mathrm{~s}$. The chest radiogram obtained in the emergency department showed pneumothorax in the left lung [Figure 1]. A chest drain was inserted in the second intercostal space by a thoracic surgeon. Pleural fluid analysis results were as follows: glucose $189 \mathrm{mg} / \mathrm{dL}$, creatinine $0.90 \mathrm{mg} / \mathrm{L}$, protein $5.25 \mathrm{~g} / \mathrm{dL}$, lactate dehydrogenase $1960 \mathrm{U} / \mathrm{L}$, amylase $11.1 \mathrm{U} / \mathrm{L}$, and albumin $2.49 \mathrm{~g} / \mathrm{dL}$. Simultaneous blood serum values of albumin were $2.57 \mathrm{~g} / \mathrm{dl}$ and total protein was $5.86 \mathrm{mg} / \mathrm{dl}$. The laboratory investigation reports obtained at the time of emergency department admission, when he was hospitalized for COVID-19 and when hospitalized for COPD exacerbation are shown in Table 1. Chest radiograms of all three periods are shown in Figure 2. His computed tomography (CT) images are shown in Figure 3, which belongs to the three most recent hospitalizations; the time he was hospitalized for COPD exacerbation and chest CT was obtained for evaluating possible pulmonary complications; second one is from when he was hospitalized for COVID-19 disease and the last one was at the time of his diagnosis of pneumothorax.

Due to the prolonged air leak, patient's chest drain was connected to the Heimlich valve, and the patient was discharged. The patient was followed up weekly, and chest

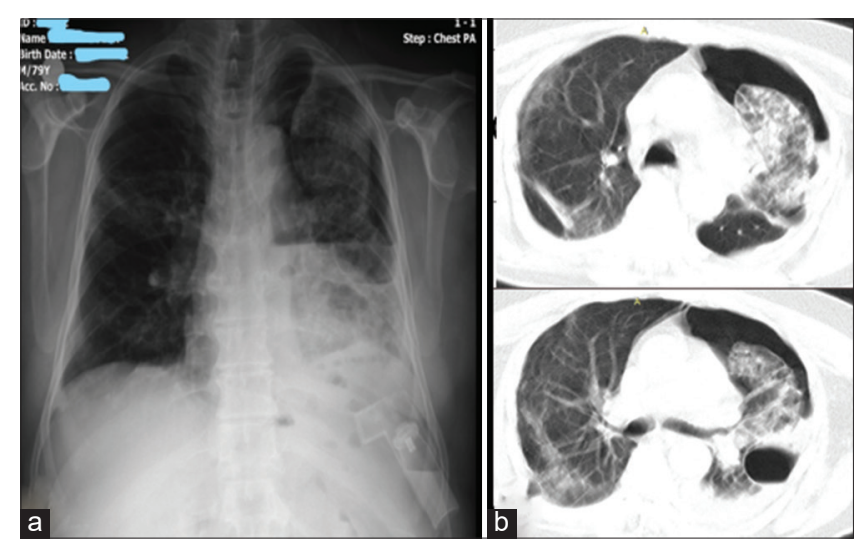

Figure 1: PA chest $X$-ray and thorax computed tomography during the admission of emergency department. (a) Pneumothorax on the left side and inhaler causing artifact. (b) Axial computed tomography images. Pneumothorax on the left lung drain was removed on the $14^{\text {th }}$ day. The patient is currently doing well and is being followed up with no complaint.

\section{Discussion}

SARS-CoV2 is a recently identified virus from the coronavirus family and causes the COVID-19 disease. It has now become a global issue, and the WHO declared it as a pandemic after 3 months from the date it was seen. Our knowledge about this novel virus is limited. Especially, the long-term effects of this virus are a matter of curiosity.

It has been reported that men are more likely to be infected with COVID-19 virus than women. Initial studies from China reported that $67.6 \%$ of patients infected with COVID-19 were men. ${ }^{[2]}$ Older patients and those with comorbid diseases are more likely to be affected by COVID-19. A Chinese study reported that $23.7 \%$ of patients had comorbid diseases. ${ }^{[5]}$ In all these studies, the most common accompanying disease was hypertension. COVID-19 is less likely to be accompanied by chronic lung diseases, compared to hypertension and diabetes mellitus. It is not understood why COVID-19 is associated with some chronic diseases and has a poor prognosis and is rarely coexisted with other diseases.

Short- and long-term effects of COVID-19 infection are still unknown. There are some expert opinions in the literature, and especially long-term lung complications are expected. Lung complications did not reach serious levels in previous viral outbreaks, and many patients returned to their normal life after treatment. ${ }^{[5]}$ Whether COVID-19 will follow a similar course is unknown. Some experts have stated that, after treatment, lung parenchyma will be damaged, and fibrosis will occur. ${ }^{[6]}$ Accordingly, reductions in respiratory functions and effort capacity are expected.

Spontaneous pneumothorax is a cardiopulmonary emergency situation. A number of respiratory disorders have been described as a cause of spontaneous pneumothorax. The most frequent underlying disorders are COPD with emphysema, cystic fibrosis, tuberculosis, lung cancer, and HIV-associated Pneumocystis carinii pneumonia, followed by more rare but "typical" disorders such as lymphangioleiomyomatosis and histiocytosis $X{ }^{[7]}$ COPD and pulmonary fibrosis are two common causes of secondary spontaneous pneumothorax in advanced age. In some COPD patients, apical pulmonary bulla or bleb can cause pneumothorax. However, previous lung images of our patient did not show any bullae or blebs. The treatment method was decided according to the severity of symptoms and the percentage of pneumothorax. The most common treatment is tube thoracostomy. In our patient, prolonged air leak was inevitable as there was diffuse parenchymal injury after COVID-19. Since the patient was planned to be discharged with the Heimlich valve, a Pezzer drain was inserted through the anterior second intercostal space.

As far as we know, there are no reports of patients presenting with a complication such as pneumothorax after receiving COVID-19 treatment recently. A review of current literature on a combination 
Oktem, et al.: COVID-19 and pneumothorax

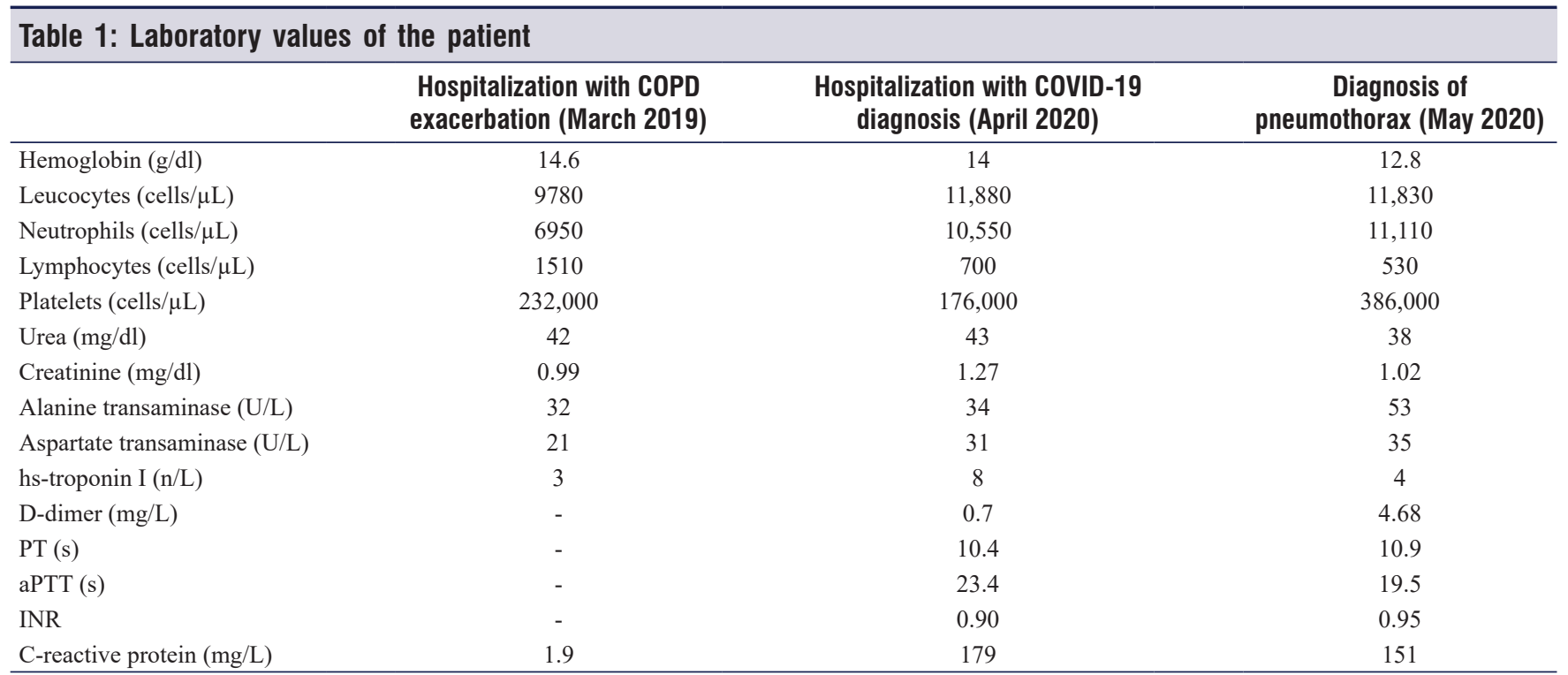

PT: Prothrombin time, aPTT: Activated partial thromboplastin time, INR: International normalized ratio, COPD: Chronic obstructive lung disease, COVID-19: Coronavirus disease 2019
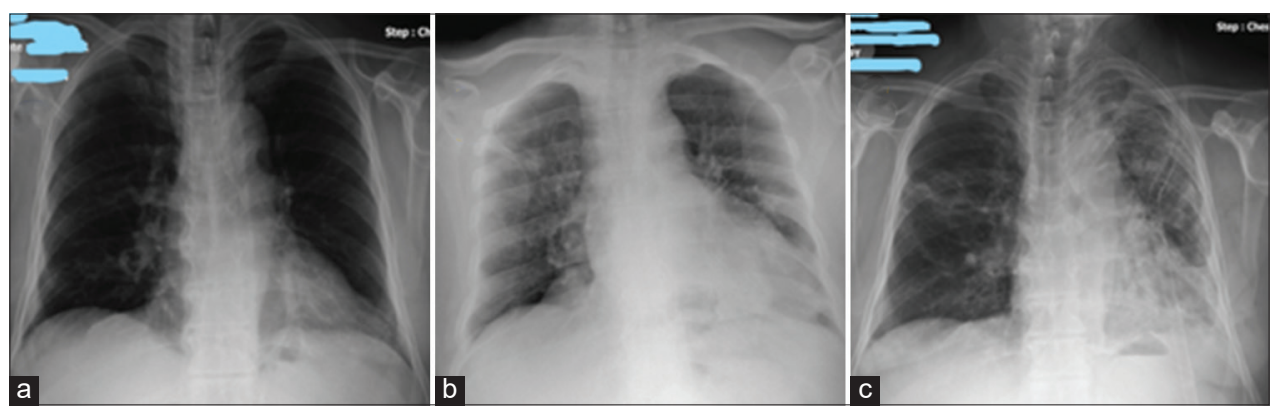

Figure 2: Chest radiogram findings of the patient (a) chest radiogram obtained during chronic obstructive pulmonary disease exacerbation (March 2019), (b) chest radiogram during hospitalization for coronavirus disease 2019 pneumonia (April 2020), (c) chest radiogram taken while having treatment for pneumothorax (May 2020)

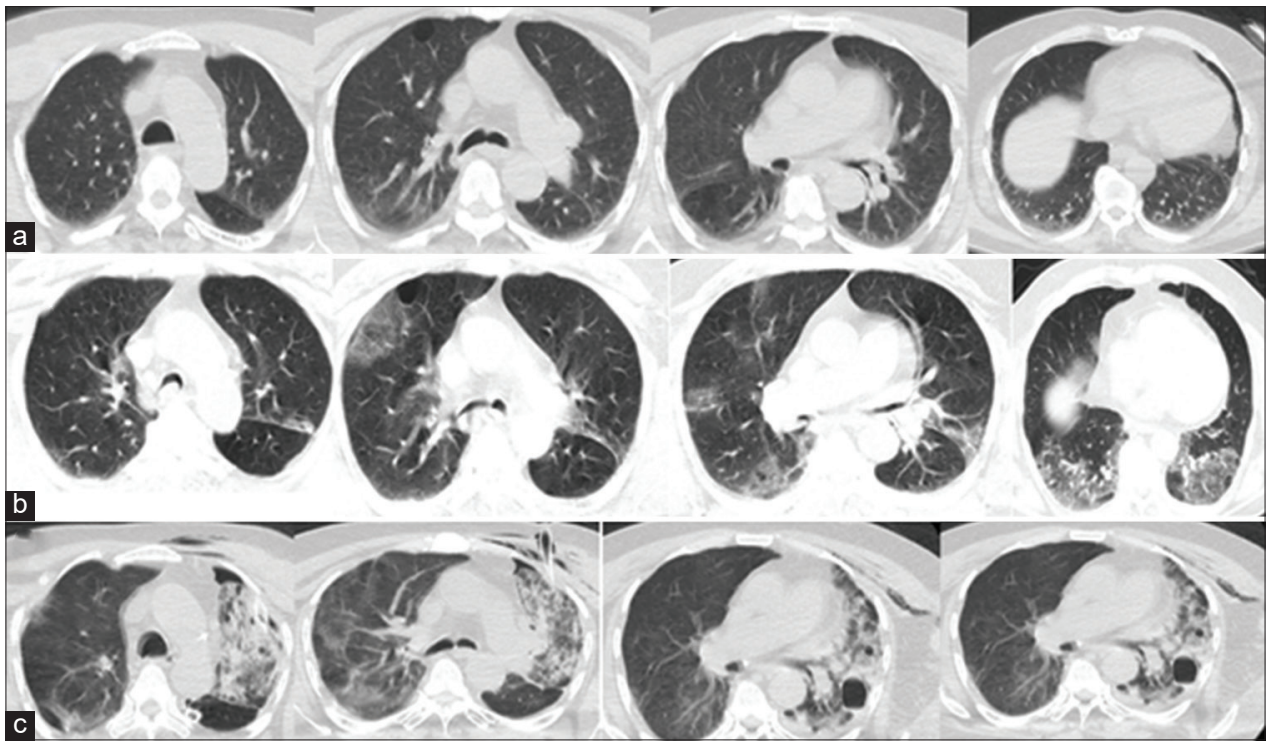

Figure 3: Computed tomography images of the patient. (a) Focal emphysema on right lung and atelectasis in lower lobes of both (May 2019), (b) Widespread ground-glass opacities, predominantly in lower lobes of both lungs (During Covid-19 diagnosis, April 2020), (c) Partially recovered areas of ground-glass in right lung; consolidation, pneumothorax, chest drainage tube and subcutaneous emphysema in left lung (After chest drainage was performed for pneumothorax, May 2020) 
of viral diseases and pneumothorax, we encountered a case of pneumothorax that was reported to be possibly associated with H1N1 virus. ${ }^{[4]}$ Our patient is an elderly person who had a comorbid disease that affects airway and lung parenchyma. Figure 3 shows the parenchymal condition of the lung before COVID-19 disease, and it can be seen that the parencymal damage had increased after COVID-19 disease. He did not have any trauma and was not using a noninvasive mechanical ventilator. The only significant feature was the recent diagnosis of COVID-19.

To conclude, COVID-19 infection is a novel disease, and our knowledge about the disease and the short- and long-term effects are limited. It will take time to fully understand the virus. Meanwhile, we think that sharing these and similar cases will contribute to the literature.

\section{Declaration of patient consent}

The authors certify that they have obtained all appropriate patient consent forms. In the form, the patient has given his consent for his images and other clinical information to be reported in the journal. The patient understands that his name and initials will not be published and due efforts will be made to conceal his identity, but anonymity cannot be guaranteed.

\section{Financial support and sponsorship}

Nil.

\section{Conflicts of interest}

There are no conflicts of interest.

\section{REFERENCES}

1. Wong HYF, Lam HYS, Fong AH, Leung ST, Chin TW, Lo CSY, et al. Frequency and distribution of chest radiographic findings in patients positive for COVID-19. Radiology 2020;296:E72-E78.

2. Chen N, Zhou M, Dong X, Qu J, Gong F, Han Y, et al. Epidemiological and clinical characteristics of 99 cases of 2019 novel coronavirus pneumonia in Wuhan, China: A descriptive study. Lancet Lond Engl 2020;395:507-13.

3. Guan W, Ni Z, Hu Y, Liang W, Ou C, He J, et al. Clinical characteristics of coronavirus disease 2019 in China. N Engl J Med 2020;382:1708-20.

4. Bor C, Demirağ K, Uyar M, Cankayalı I, Moral AR. Recurrent spontaneous pneumothorax during the recovery phase of ARDS due to H1N1 infection. Balkan Med J 2013;30:123-5.

5. Chen J, Wu J, Hao S, Yang M, Lu X, Chen X, et al. Long term outcomes in survivors of epidemic influenza A (H7N9) virus infection. Sci Rep 2017;7:17275.

6. Salehi S, Reddy S, Gholamrezanezhad A. Long-term pulmonary consequences of coronavirus disease 2019 (COVID-19): What we know and what to expect. J Thorac Imaging 2020;2020;8:666-7. https://doi. org/10.1097/RTI0.0000000000000534.

7. Noppen M. Spontaneous pneumothorax: Epidemiology, pathophysiology and cause. Eur Respir Rev 2010;19:217-9. 